\title{
Ayla Kutlu'nun Yıldız Yavrusu Adlı Çocuk Romanında Toplumsal Cinsiyet Rolleri Açısından Değișen Baba Figürü
}

\author{
Ali KURT* \\ Ece Burçin AYAZ**
}

Öz

Çocuk edebiyatı, bireyin kimliğinin oluşmasına katkı sağlaması açısından önem arz eder. Edebî olmanın yanında didaktik yönü de bulunan bu eseler, çocuk gelişiminin ve edebiyatın ortak noktada buluştuğu önemli bir sahadır. Bireyin kimliğini kazanmasında toplumun kendisine yüklediği misyonla birlikte cinsiyeti de etkilidir. Bireylerin belli bir misyonla yetiştirilmesi düşüncesi bazen açık bazen örtük bir program olarak çocuk edebiyatı ürünlerinde de karşımıza çıkmaktadır. Çocuk edebiyatı ürünlerinde toplumsal cinsiyet rollerinin izi sürüldüğünde büyük ölçüde bu programın da izi sürülmüş olur. Bu çalışmada, Ayla Kutlu'nun Ylldız Yavrusu adlı çocuk romanında toplumsal cinsiyet rolünden hareketle değişen baba figürü üzerinde durulacaktır. Ayla Kutlu'nun çocuk romanlarında toplumsal cinsiyet rolleri, bazen yaşanmış ya da yaşanabilme imkânı olan bir kurmaca dünyada bazen de çağdaş masal formunda karşımıza çıkmaktadır. Yıldız Yavrusu romanında, geleneksel cinsiyet rollerinin yerine modern toplumların aile yapısında şahit olunan cinsiyet rollerinin ikame edildiği; yine bu yapı içinde de özellikle değişen baba figürünün ve bir çağdaş masal diliyle bile olsa örtük bir cinsel kimlik tercih özgürlüğünün ele alındığı görülmektedir.

Anahtar Kelimeler: Çocuk Edebiyatı, Toplumsal Cinsiyet, Baba Figürü, Ayla Kutlu

\footnotetext{
* Dr. Öğretim Üyesi, Kırklareli Üniversitesi, Fen Edebiyat Fakültesi, Türkiye. Elmek: alikurt27@gmail.com

** MEB, Öğretmen, Türkiye.

Elmek: eceburcinayaz@windowslive.com
} 


\title{
The Changing Father Figure In Terms of Gender Roles In Ayla Kutlu's Children's Fiction Book Yıldız Yavrusu
}

\begin{abstract}
It is known that children's literature, which has a didactic purpose besides being literary, has a contributing effect on the formation of an individual's own identity. An individual who is born with a biological gender acquires his or her identity through missions assigned by the society. The idea of raising individuals with a certain mission is sometimes seen as an open or a hidden curriculum in children's literature texts. When the traces of gender roles are examined in those texts, this curriculum will also be traced to a great extent. In this study, the image of the changing father in Ayla Kutlu's children's fiction Ylld $z$ Yavrusu will be examined in terms of gender. Social gender roles in Ayla Kutlu's children's novels can sometimes be seen in a fictional real world or in the form of a contemporary fairy tale. In the novel Ylld $z$ Yavrusu, it is seen that the traditional gender roles are replaced by those witnessed in the family structure of the modern societies, and that particularly the changing father figure is reflected in this structure as well as an implicit freedom of gender identity even if it is expressed in the language of a contemporary fairy tale.
\end{abstract}

Keywords: Children's Literature, Gender Roles, Father Figure, Ayla Kutlu 


\section{Giriş}

\section{Toplumsal Cinsiyet Rolleri}

Cinsiyet kavramı, bireylerin biyolojik türlerini ifade ederken; toplumsal cinsiyet, bu biyolojik türlerin her toplumun kendi yapısı içinde şekillenmesi ile ilgili kavramı karşılamaktadır. Diğer bir ifadeyle toplumsal cinsiyet, biyolojik bir türden farklı olarak, kadın ve erkeğin sosyal ve kültürel açıdan tanımlanmasını, toplumların bu iki cinsi birbirlerinden ayırt etme şekillerini ve onlara yüklediği toplumsal rolleri anlatmak için kullanılan kavramıdır. (Ecevit ve öte..,2011: 4) "Cinsiyet makro düzeyde kaynakların dağılımı ile kültürel inançları, bireysel düzeyde kişilik ve kimlikleri, etkileşimsel düzeyde ise davranış biçimleri ile durumsal yapıları içeren bir sistemdir." (Ridgeway, Shelley, 2000: 110) Her toplum kendine özgü kuralları ile cinsiyet kimliğini oluşturur. Maskülen veya feminen olarak adlandırılan davranışlar, nesilden nesile aktarılarak cinsiyetin toplumsallaşmasını sağlar. “... Toplumsal cinsiyet, kadınlar ile erkekler arasındaki farkl1lıkların toplumsal düzlemde kurulmuş yönlerine"( Marshall, 1999: 98) vurgu yapar. Geleneksel toplum, kadın kimliğine şefkatli, fedakâr, naif gibi duygusal özellikleri uygun görürken erkek kimliğine güçlü, sert, özgür gibi sosyal rolleri yakıştırır. İçerisine girdiği çevreye göre kimlik kazanmaya başlayan erkek ya da kadın cinsiyeti farklılaşmaya başlar. Bazı kuramlara göre bu farklılaşma gerekli görülmektedir. “...Gelişmekte olan ve gelişmiş/sanayileşmiş toplumları gözlemleyen yapısal-işlevselciler, düzenin sürekliliğinde cinsiyet rolü farklılaşmasının gerekli olduğunu ileri sürerler.” (Taşkın, 2008: 127) Aile kurumunu toplumsal düzenin temel döngüsü kabul eden yapısal fonksiyonalizmin kurucusu Parsons da cinsiyet hiyerarşisinin varlığını dile getirerek eşlerin aile içinde birbirini tamamlayan ve uzmanlaşmış rolleri olduğunu; erkeğin araçsal, kadının dışavurumsal rolü üstlenmesi gerektiğini belirtmiştir. (Özgün; Güner, 2011: 3)

Kadın ve erkeğin içinde bulunduğu topluma göre şekillenen roller, özellikle geleneksel toplumlarda belirgin şekilde ayrılır. Erkeğe ailesini korumak ve maddi anlamda ailenin geçimini sağlamak gibi görevler verilmişken kadın çocu- 
ğunu yetiştirmek ve ev içi rolleri yerine getirmekle sorumlu tutulur. Baba ailenin otoritesine; anne ise babadan geri planda temizlik ve çocuk bakımı ile ilgilenen bir role sahiptir. Geleneksel toplumlarda kadın eve ait kabul edilmiş bunun dışında olduğu her yerde tehlikede olduğu varsayılmıştır. Evde çocuklarını büyütmekle sorumlu tutulan kadın toplumun ona yüklediği misyonla "eş" veya "anne" olma durumunu içselleştirmiştir.

Geleneksel toplumlarda erkeğe ise çalışkan, enerjik ve otoriter olma, evini koruma ve maddi kazanç sağlama rolü biçilmiştir. Cesur ve korkusuz olması beklenen erkeğin acizlik göstermemesi, ağlamaması, fedakâr ve nazik olmaması öğretilir. Kendisine biçilen rolü yerine getiren erkek kimliği, kadına göre kadına göre daha üstün bir hâle gelmektedir. Kadınların kendilerinden aşağı olduğunu düşünen erkek toplumsal çevre tarafından buna inandırılır ve kadın kimliğini kendisine yardımcı olarak görmeye başlar. Toplumun kendisine verdiği rolü içselleştiren erkek birçok duygusunu sinırlandırır. Toplumsal cinsiyet rolünün erkek kimliğine verdiği üstünlük ile kadın kimliği de erkeğe verilen toplumsal rolü benimseyerek erkeğe boyun eğmekle görevlendirildiğini kabul etmiş̧ir. Ancak toplumların değişmeye başlaması, kadın-erkek rollerinin de değişmesini sağlamıştır. Modern toplumlarda toplumsal cinsiyet eşitliğine inanılmış, kadın ve erkeğin her şeyden önce insan olarak hak ve sorumluluklarının olduğu düşünülmüştür. Görevlerinin birbirinden farklı olduğu kabul edilmekle birlikte cinsiyet rolleri artık eşit hâle gelmiştir. Erkekler de kadınlar kadar duygularını özgürce belli etmeye, aynı zamanda çalışma hayatın içindeki kadınlara ev işlerinde de yardımcı olmaya başlamıştır. Çocuk bakımı sadece kadının görevi gibi görülmeyip baba olarak erkek de bu konuda kadına destek vermiştir.

\section{Çocuk Edebiyatının Bireyin Kimlik Oluşumundaki Yeri}

Yetişkin edebiyatının taşıdığı bütün niteliği taşımakla birlikte eğitici yönüyle öne çıkan bir edebiyat (Şimşek, 2014: 15) olarak da niteleyebileceğimiz çocuk edebiyatının çocuklara okuma sevgisi ve alışkanlığı kazandırmasına edebiyat duyarlılığının gelişmesine ve bireyin kendi kimliğinin oluşmasına katkı sağlamak gibi çok geniş bir etki alanı olduğu bir geçektir. (Dilidüzgün, 1996: 27) Bu sebeple toplumların geleceklerini şekillendirmedeki tartışılmaz misyonu olan çocuk 
edebiyatı; ister istemez kendi düşünce dünyaları ve beğenileriyle şekillendirilerek ideal ve makbul insan yetiştirme arzusu içinde olan bütün ideolojilerin, ideallerini gerçekleştirmek için en uygun zemin olarak düşündükleri bir alan da olmuştur. Biyolojik olarak bir cinsiyete ait dünyaya gelen birey, toplumun kendisine yüklediği misyonla toplumsal kimliğini kazanır. İște bireyleri belli bir misyonla yetiştirmemiz gerektiği düşüncesi bazen açı bazen de örtük bir program olarak çocuk edebiyatı ürünlerinde de karşımıza çıkmaktadır. Çocuk edebiyatı ürünlerinde toplumsal cinsiyet rollerinin izini sürdüğümüzde kısmen bu programın da izini sürmüş oluruz.

\section{Ayla Kutlu'nun Yıldız Yavrusu Adı Çocuk Romanında Toplumsal Cin- siyet Rolleri ve Değişen Baba Figürü}

Ayla Kutlu'nun Ylldız Yavrusu adlı çocuk romanında toplumsal cinsiyet rollerinin izi sürüldüğünde modern toplumlarda karşımıza çıkan cinsiyet rollerinin ikame edilmeye çalışıldığı, hatta birçok toplum için tabu durumunda olan cinsel kimliğin bir tercih konusu olabileceği hususunun bile bu çocuk romanında işlenebildiği görülmektedir. Jung çocuğun psikolojik yaşam serüvenini şöyle anlatır:

Çocuk psikolojik yaşamına dar sınırlar dahilinde sihirli anne ve aile çemberi içinde başlar. İlerici olgunlaşma ile ufkunu ve kendi etki alanını genişletir; umutları ve niyetleri, kişisel gücünü ve sahip olduklarını genişletmeye yönlendirilir; arzu devamlı genişleyerek dünyaya erişir; bireyin iradesi bilinçdı̧ı güdüler tarafindan takip edilen doğal hedeflerle daha da özdeş hale gelir. (Jung, 2015: 104)

Ayla Kutlu çocuk romanlarında erkek kimliğini genellikle baba rolü ile karşımıza çıkarır. İnsanlık tarihi incelendiğinde baba figürü, geleneksel toplumlardaki değer normlarında ailenin koruyucu gücü iken değişen hayat şartları ile ailenin hem manevi hem de fiziki anlamda yanında duran kadın kimliğiyle eşit bir role bürünmüştür. Yazarın bu eşitlenmeyi tüm çocuk romanlarına yansıttığ görülmektedir. Geleneksel cinsiyet rolleri yerine modern toplumlarda öne çıkan cinsiyet rollerini benimseyen yazar, romanlarında bu roller içinde önemli bir yeri olan modern baba figürünü de çocuk okuyucularına benimsetmeye çalışmaktadır. Buradan hareketle yazarın, cinsel kimliğini yeni oluşturmaya başlayan bir çocuğun okuduğu kitaplardan etkileneceğini düşünerek toplumda yeni ve modern cinsiyet rollerini inşa etmeye çalıştığı söylenebilir. 
Ylldız Yavrusu romanında yazar, babanın görevini anneyi ve yavrularını tüm kötü güçlere karşı korumak olarak verir. Ancak babanın bu koruma görevi geleneksel bir koruma şeklinde değil de aileyi dışarıdan koruyan ve gelecek tüm tehlikelere karşı tedbir alacak olan bir figür şeklindedir. Nitekim geleneksel ailelerde kadın daima erkeğin gölgesindedir (Jung, 2015: 38) ve bu nedenle aileyi koruma rolü baba üzerindedir. Yazar bu geleneksel kalıplara karşı çıarak güçlü koruyucu baba figürünü, değişen hayat şartları ile birlikte modern baba çizgisine dönüştürmeye çalışmışıtır. Romanda babanın aileden uzak yaşamasıyla yazarın, gelişmiş toplumlarda anne ve babası ayrı yaşayan aileleri yansıtmak istediği söylenebilir. Öyle ki, baba ve çocuk ilişkisinin geleneksel toplumlardaki gibi bir arada olmak zorundalığını kaldıran yazar, baba olmadan da ailenin ayakta durabileceği izlenimini verir. Nitekim bireyselliğin önem kazandığı modern toplumlarda baba koruyucu güç olmaktan çıkmıştır. Yıldız Yavrusu romanının başkahramanı Ramram, annesine babalarının neden aileden uzak yaşadığını sorar. Annesin bu konuda yavrusuna verdiği cevap oldukça dikkat çekicidir. Romanda bu diyalog şöyle verilir:

“...-Babamız mı? Peki biz niçin babamızdan ayrıyız?

-Bizim evrenimizin kuralı böyledir de ondan. İlkemiz, varlığın kendine yetmesi ve başının çaresine bakabilmesidir." (Kutlu, $2012: 31$ )

Görüldüğü gibi araçsal bir role sahip olan baba, özellikle batı toplumlarında evin maddi ihtiyaçlarını dahi karşılamak konusunda serbest bırakılmış, çoğu görevi anneye teslim etmiştir. Oysaki geleneksel toplumlarda baba ailenin otoritesine; anne ise babadan geri planda temizlik ve çocuk bakımı ile ilgilenen bir role sahiptir. "Kadının para kazanma işlevine katılmasıyla geleneksel aile düzeninin dayandığı ayrışmış kadın-erkek rolleri yerini paylaşmaya dayalı cinsiyet rolleri anlayışına bırakmıştır ." ( Fortin, 2005: 419) Yazarın, burada babanın kentleşmeyle birlikte ortadan kalkan ancak geleneksel bir yaşam tarzı benimseyen ailelerde henüz tam anlamıyla etkisini kaybetmeyen Evin reisi algısını da kırmaya çalıştığı ortadır. Burada annenin kullandığı varlığın kendine yetebilmesi ifadesiyle yazarın, geleneksel ailelerde görülen erkek egemen boyunduruğuna kahramanlar üzerinden itiraz ettiğini ve çocuk okuyucularının bilinçaltına "kendi kendine yetebilme" fikrini atmak istediğini söylemek mümkündür. 
Yine aynı romanda yazarın, yıldız yavrularının babalarından ayrı büyümelerinin günümüz toplumlarında artan boşanmalarla beraber çocukların baba figüründen uzak büyümelerini göz önünde bulundurarak artık doğal ve sıradan bir olay olan bu durumun çocukların gözünde de alelade bir durum gibi görülmesini meşrulaştırmak istediği söylenebilir. Romanda tehlikeli uzay canavarları aileye saldırır. Anne ve çocukları oldukça korkmuştur ancak Anne bu tehditten kurtulmak için tek başına mücadele eder. Babalarının yardım edemeyişi ve ailenin kendi başlarının çaresine bakmaları ile yazar, baba olmadan da ayakta durabilen bir aile modelini gözler önüne serer. Romanda ayrıca geleneksel toplumun babaya yüklediği “güçlü baba rolü” nün pasivise edilerek annenin güçlü ve kurtarıcı bir role büründüğü de görülmektedir. Bu durum romanda şu şekilde geçer:

Anne yavrularına seslendi:

Hangi gezegene giderseniz gidin... Oranın koşullarında yaşamanız için uyum yeteneğiniz gerçekleşti. Artık başka seçeneğim kalmadi. Bir tohum tanesi kadar kalsam bile gidip babanızı bulacağım ve sonra sizleri gittiğiniz yerden alacağım. Buna inanın. (Kutlu, $2012: 36)$

Bununla beraber roman kahramanı Ramram'ın annelik ve babalık kavramları hakkında kafası karışır. Ramram, annesinin ve babasının yüklendiği farklı sorumlulukları görünce büyüdüğü zaman anne mi yoksa baba mı olacağı sorusu aklına takılır ve annesine bunu sorar. Bu soru üzerine anne, yıldız uzay sonsuzluklarında fonksiyonların çeşitlendiğini ancak kesin hatlarla ayrılmadı̆̆ını ister anne isterse de baba olabileceklerini söyler. Yazar, cinsiyet seçimlerinde cinsel edinimin toplum tarafından kabul edilebilirliğini yıldız yavruları aracılı̆̆ıyla sorgular. Özellikle günümüz toplumunda cinsellik ifadesinin özgür bir seçim olarak sunulmasıyla cinsel kimlik tercihleri daha serbest bir hal almıştır. Belli bir toplumsal duruma ilişkin gerçek davranış kalıpları ya da beklenen davranış kalıplarını ( Tan, 1979: 158) kırmak üzere yazarın, bu serbestliği cinsiyet kimliği kazanmaya başlayan çocuk okuyuculara vermeye çalıştığı söylenebilir. Yıldız yavrularının ileride hem anne hem de baba olabileceklerini; annenin söylemesiyle çocukların cinsel kimlik algıları oluşmaya başlar. Erkeğin ayrıcalıklı konumunu (Adler, 2013: 14) reddeden yazarın, geleneksel toplumlardaki kadın rolünden duyulan hoşnutsuzluğu göz önünde bulundurarak çocuk okuyuculara gönüllü bir şekilde bu rolü üstlenebilme bağımsızlı̆̆ını verdiği söylenebilir. Nitekim, ebeveyn- 
lerinden birinin cinsel kimliğini edinecek olan çocuk, özgür iradesiyle toplumsal cinsiyet rolünü de belirlemiş olacaktır. Bununla beraber Yıldız Yavrusu romanında geçen kahramanların cinsiyetlerinin verilmemesiyle yazarın çift cinsiyetliliğe de vurgu yaptığ 1 düşünülebilir. Geleneksel toplumlarda doğuştan gelen biyolojik cinsiyet reddedilerek karşı cinsi veya her iki cinsi bir arada yaşamak yasak kabul edilmesine ve hatta bu durumun ağır bir şekilde cezalandırılıyor olmasına karşılık modern toplumlarda artık bu durum daha normal görülmektedir. Bu bakımdan romanda kahramanların cinsiyetlerinin belirsizliği ya da çocuğun cinsel kimliğinin değişebilmesi ile yazarın toplumsal cinsiyet rollerine karşı çıtığını söylemek mümkündür. Ylldız Yavrusu romanında anne ve babalık rolünün kişinin isteğine göre verilmesi meselesi Ramram'ın annesinin ağzından şöyle anlatılır:

"Uzay sonsuzluğunda fonksiyonlar çeşitlenmiş ama kesin çizgilerle ayrılmamıştır. Ben anneliği yaşamak istedim. $\mathrm{O}$ zaman eşim babalık görevini üstlendi. Milyonlarca 1şık yılı sonra belki o anne olmak ister. Ben de babalık fonksiyonlarını gerçekleştirebilirim. Ramram kekeledi: Şimdi ben... Yani büyüyünce istersem anne istersem baba mı olacağım? ...Bu çok hoş anne” (Kutlu, 2012 :32)

Romanda görüldüğü gibi çift cinsiyetliliğin utanılacak bir durum olmaktan ç1ktığı günümüz toplumlarında bir seçime dönmüşsür. Cinsiyet seçimi konusunda baskının olmadığı bu durum ile Yıldız Yavrusu kendi cinsel kimliklerini belirleyecek ve rollerini de buna uygun yaşayacaklardır. Yazar, çift cinsiyetliliği vurgulamasıyla çocuk okuyucularının zihninde toplumsal cinsiyet rollerinin eşitsizliğini kaldırmak istemiş de olabilir. Nitekim yazarın erkek ya da dişi olarak insanın ayrılmaması gerektiği iki rolün de birbirinden farklı görevleri olduğu ve bu yüzden hiçbir toplumsal cinsiyetin bir üstünlüğü ya da aşağı yanı olmadığını yıldız anne ve babanın görevleri ile belirttiğini söylemek mümkündür. Yazar burada belki de kadın-erkek eşitliliğini vurgulamak istemiş, çocukları toplumsal cinsiyet rollerinin eşitliliği bilincine ulaşmalarını sağlamak için böyle bir olayı kurgulamış olabilir. Ancak bu romanı okuyacak çocukların tam da cinsel kimliklerinin oluştuğu dönemde doğuştan gelen cinsel kimliklerini yok farz eden ve bu durumu bir tercih meselesi gibi bilinçaltına atabileceği gerçeği göz ardı edilmemelidir. Yazar bilinçli olarak bunu yapmadıysa bile pedagojik açıdan sorumlu davranmamış olduğu ortadadır. 


\section{Sonuç}

Ayla Kutlu'nun Yıldız Yavrusu adlı çocuk romanında, baba figürünün izi sürülünce modern toplumlarda karşımıza çıkan "baba" cinsiyet rolünün ikame edilmeye çalışıldığı görülmektedir. Romanda geleneksel toplumlardaki değer normlarında ailenin koruyucu gücü olan baba; değișen hayat şartları ile ailenin hem manevi hem de fiziki anlamda yanında duran kadın kimliğiyle eşit bir role büründüğü görülmüştür. Geleneksel cinsiyet rolleri yerine modern toplumlarda öne çıkan cinsiyet rollerini benimseyen yazar, romanında bu roller içinde önemli bir yeri olan modern baba figürünü çocuk okuyucularına benimsetmeye çalıştığı söylenebilir. Aynı zamanda yazar, birçok geleneksel toplum için tabu durumunda olan cinsel kimliğin bir tercih konusu olabileceği hususunu da romanında işlemiştir. Buradan hareketle yazarın, cinsel kimliğini yeni oluşturmaya başlayan bir çocuğun okuduğu kitaplardan etkileneceğini düşünerek toplumda yeni ve modern cinsiyet rollerini inşa etmeye çalıştı̆̆ da söylenebilir. Bununla beraber yazarın, geleneksel ailelerde görülen erkek egemen boyunduruğuna kahramanlar üzerinden itiraz ettiğini ve çocuk okuyucularının bilinçaltına "kendi kendine yetebilme" fikrini aşılamak istediği görülür. Romanda erkeğin ayrıcalıklı konumunu reddeden yazar, geleneksel toplumlardaki kadın rolünden duyulan hoşnutsuzluğu çocuk okuyuculara gönüllü olarak bu rolü üstlenebilme bağımsızlığını vermek istediği söylenebilir. Yazarın romanda, çift cinsiyetliliği vurgulamasıyla çocuk okuyucularının zihninde toplumsal cinsiyet rollerinin eşitsizliğini kaldırmak istediği de görülmektedir ancak bu romanı okuyacak çocukların tam da cinsel kimliklerinin oluştuğu dönemde doğuştan gelen cinsel kimliklerini yok farz eden ve bu durumu bir tercih meselesi gibi bilinçaltına atabileceği gerçeği göz ardı edilmemelidir. Yazar bilinçli olarak bunu yapmadıysa bile pedagojik açıdan sorumlu davranmamiştır. 


\section{Kaynakça}

Adler, A. (2013). İnsan Doğasını Anlamak, çev. Deniz Başkaya. İzmir: İlya Yayınları.

Dilidüzgün, S. (1996). Çağdaş Çocuk Yazını, İstanbul: Yapı Kredi Yayınları.

Ecevit, Y. ve öte. (2011). Toplumsal Cinsiyet Sosyolojisi. Eskişehir: Anadolu Üniversitesi Yayınları.

Fortin, N. (2005). "Gender Role Attitudes and the Labour-Market Outcomes of Women Across OECD Countries." Oxford Review of Economic Policy, Mart 2005, Say1:21

Güner, G. ve Özgün B. (2011). "Kadınların Toplumsal Cinsiyet Rolleri Çerçevesinde Aile İçi Yaşamı Algılama Biçimleri”, TSA, Aralık 2011

Jung, G. (2015). Feminen Dişilliğin Farklı Yüzleri, çev. Tuğrul Veli Soylu. İstanbul: Pinhan Yayıncilık

Kılıçoğlu, E. B. (2016), Ayla Kutlunun Çocuk Edebiyatı Ürünlerinde Toplumsal Cinsiyet Rolleri. Kırklareli: Kırklareli Üniversitesi Sosyal Bilimler Enstitüsü Türk Dili ve Edebiyatı Anabilim Dalı, (Danışman: Yrd. Doç. Dr. Ali kurt) Basılmamış Yüksek Lisans Tezi

Marshall, G. (1999), Sosyoloji Sözlüğü, ( Çev.: Osman Akınhay\Derya Kömürcü), Ankara: Bilim ve Sanat Yayınları,

Ridgeway, C. ve Shelley, C. (2000), "Limiting İnequality through İnteraction: The End(s) of Gender", Contemporary Sociology, January 2000, Vol. 29, No: 1

Şimşek, T. (2014), “Çocuk Edebiyatı Tarihine Ön Söz”, Çocuk ve İlk Gençlik Edebiyatı Özel Sayıs1, Türk Dili Dergisi, Aralık 2014, Sayı: 756

Tan, Mine (1979), Kadın: Ekonomik Yaşamı ve Eğitimi, Ank: Türkiye İŞ Bankası

Taşkın, E. (2008) “Toplumsal Sistemin Düzen Sağlayıcı Unsuru Olarak Cinsiyet Rolü Farkl1laşması" Türkiye Sosyal Araştırmalar Dergisi, 3, 4, 2008 